\title{
The Effects of Mixing Pulp and Paper Mill Sludge Into Wood Bark on Storage-Related Environmental Impacts and Heating Value
}

\author{
Juha Oksanen ${ }^{1}$ D $\cdot$ Riikka Keskinen ${ }^{2} \cdot$ Jaakko Heikkinen $^{2} \cdot$ Janne Kaseva $^{2} \cdot$ Kimmo Rasa $^{2}$
}

Received: 14 June 2021 / Accepted: 6 February 2022 / Published online: 7 March 2022

(c) The Author(s) 2022

\begin{abstract}
The pulping industry generates vast amounts of bark and wastewater treatment sludges, which are combined and stored in stacks, often in the open air, prior to combustion for energy. The effects of incorporating sludge into bark on heating value and storage-related environmental impacts were investigated in laboratory and outdoors. Biological degradation was found to be higher in treatments containing 25\% sludge (B75S25) and 50\% sludge (B50S50) in comparison with pure bark (B100). Mean monthly dry mass loss was 2.1\% (B100), 3.3\% (B75S25), and 3.7\% (B50S50) in the laboratory and 2.7, 4.2, and 4.8\%, respectively, outdoors. Addition of sludge maintained degradation activity at low temperatures $\left(+3{ }^{\circ} \mathrm{C}\right)$. Co-storage of sludge and bark led to loss of energy, mainly due to increased loss of biomass and increased moisture, which governed the heating value. Cumulative methane emissions were higher from the sludge-containing treatments than from pure bark, but emissions of nitrogen-containing gases $\left(\mathrm{N}_{2} \mathrm{O}\right.$ and $\left.\mathrm{NH}_{3}\right)$ were negligible throughout. Sludge addition roughly halved the cumulative chemical oxygen demand (COD) of leachate and minimized its concentration of phosphate-P. However, larger amounts of inorganic elements were released from the sludge-containing treatments. Overall, these results indicate that finding alternative uses for the sludge fraction would be beneficial.
\end{abstract}

\section{Graphical Abstract}

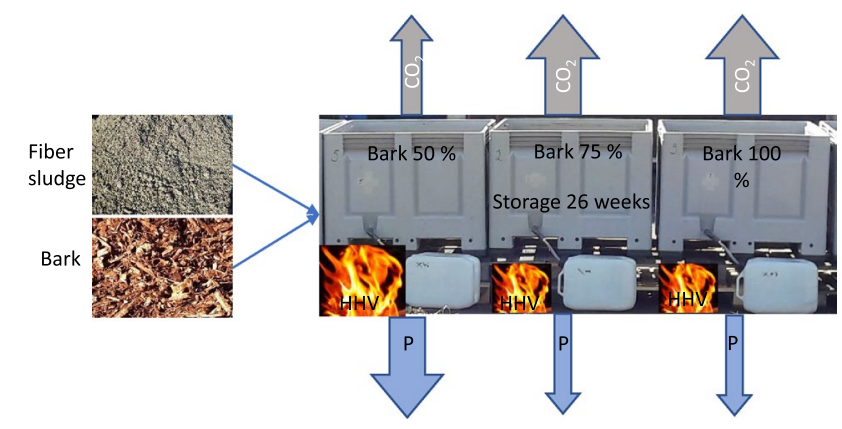

Keywords Wood pulp. Biological degradation · Energy value · Wood storage · Bark utilization

Juha Oksanen is a doctoral student at Aalto University, Finland.

Juha Oksanen

juha.oksanen@storaenso.com

1 Division Biomaterials, Pulp Competence Centre, Imatra Research Centre, Stora Enso, FI-55800 Imatra, Finland

2 Management and Production of Renewable Resources, Natural Resources Institute Finland, Tietotie 4,

FI-31600 Jokioinen, Finland

\section{Statement of Novelty}

The objective of this study was to gain knowledge on the interaction of effluent treatment derived sludge with bark when stored together. This kind of co-storage is the standard practice in the pulp and paper industry, where most of the sludge is still burned together with other side stream biomasses, usually bark. The need to assess the sustainability 
of waste biomass management strategies was brought forth by the pulp industry.

The study showed that storing bark combined with sludge has a negative effect on the total energy content of the biomass. The adverse effect of sludge was caused by increased rate of biological degradation and higher moisture content.

\section{Introduction}

Wood residues and wastewater treatment sludges are the main solid waste streams generated by the pulp and paper industry [1]. Wood residues consist mainly of bark falling from the debarking drum during the first steps of pulp wood handling. Treatment sludges can be divided into primary sludge, containing fibers removed from process effluent through sedimentation, and biosludge, originating from secondary biological treatment of the effluent and often also wastewater from sanitary facilities [2]. These sludge types are typically combined and thickened by compression, and finally combusted together with wood residues to recover energy for the pulping process $[1,3]$. However, there are many other established and emerging ways of utilizing the sludge. For energy recovery, anaerobic digestion and pyrolysis are possible alternatives. Other options include application to agricultural land [4] and integration with other materials [5].

Mills often have to store considerable amounts of bark and sludge, as generation of these wastes is time-dependent. The two fractions tend to be mixed in stacks in the storage area, usually an open field. In terms of energy production, preserving the heating value of the fuel during storage is essential. Studies on various forest residues have shown that, depending on climate conditions, dry matter losses of $1-10 \%$ per month can occur due to biological and chemical degradation of the wood material [6]. Blending pulp sludge into bark can be assumed to accelerate the dry matter loss rate, as additional nitrogen $(\mathrm{N})$ and other nutrients, moisture, and greater surface area are introduced to the mixed biomass within the sludge. Although degradation of lower value carbohydrates may lead to a more energy-dense fuel, the overall loss of biomass material inevitably decreases the energy content available. Furthermore, the rather high moisture and ash content of the sludge render it inherently less valuable than bark as a fuel $[1,7]$.

Besides loss of biomass, degradation produces emissions of climate-relevant gases [8]. Wihersaari [9] estimated that emissions of greenhouse gas, namely methane $\left(\mathrm{CH}_{4}\right)$ and to a lesser degree nitrous oxide $\left(\mathrm{N}_{2} \mathrm{O}\right)$, from forest residue stacks may be a concern. Gaseous emissions tend to increase with increasing dry matter losses [10]. Assuming that introducing sludge to bark increases degradation, it can be hypothesized that combined bark-sludge storage leads to higher greenhouse gas emissions than from stacks containing only pure bark.

Since the waste stacks are stored outside with no cover, they are exposed to rainfall and snow. Water percolating through wood wastes is known to leach nutrients, metals, and organic compounds, e.g., lignins, tannins, and fatty acids, from the material [11-13]. The pulping sludge may also contain and release nutrients, metals, and chemical toxicants, depending on the process and the effluent treatment applied [14, 15]. Besides causing aquatic toxicity, the organic load in the leachate induces high oxygen demand in the receiving water body [16]. The influence of sludge addition on the quality of bark leachate is not known.

This study investigated the effects of combining wood pulp sludge with wood bark waste on the degradation rate during storage and on post-storage heating value of the final biomass, compared with storing only wood bark waste. First, sludge and bark mixes were studied in a controlled laboratory environment, and then a larger-scale outdoor storage study was carried out in uncovered containers. Greenhouse gas emissions and quality of percolating water were monitored throughout the outdoor storage period. The aim was to provide important information on best management of the solid waste fractions generated in pulp mills as studies of this kind on sludge-bark interactions could not be found in the recent literature. The need to optimize storage strategies of side streams is increased recently due to the requirements to promote circular economy and to curb the climate change.

\section{Materials and Methods}

\section{Raw Materials}

The wood bark and pulp mill sludge used in the study originated from Stora Enso's Imatra mill in eastern Finland. The bark was a mixture from softwood and hardwood trees, obtained by the dry-debarking method. The sludge, which was derived from the effluent treatment plant at the mills, contained roughly $30 \%$ biosludge from the active sludge treatment and $70 \%$ fiber-rich primary sludge from sedimentation. These two types of sludge were mixed during sludge handling and dried with screw presses to a solids content of $30-35 \%$. The biomasses were collected freshly processed in February 2017 and transported directly in separate trailers to the laboratory of the Natural Resources Institute Finland (Luke) at Jokioinen in southern Finland.

Immediately after arrival, representatives samples of around $150 \mathrm{~L}$ of bark and $50 \mathrm{~L}$ of sludge were collected from the corresponding piles and placed separately in cold storage $\left(+6{ }^{\circ} \mathrm{C}\right)$, from where they were taken for a laboratory incubation experiment starting on the following day (see Sect. "Laboratory incubation"). The remaining bulk of the sludge 
and bark were stored outdoors on plastic sheets in two separate piles, covered with separate plastic sheets, before being used in the outdoor storage experiment in late April 2017 (see Sect. "Outdoor storage"). During the 65-day pre-storage period, mean daily temperature was $+0.3{ }^{\circ} \mathrm{C}$, ranging from -8.1 to $+5.5^{\circ} \mathrm{C}\left(23\right.$ days $<0{ }^{\circ} \mathrm{C}, 4$ days $\left.>5{ }^{\circ} \mathrm{C}\right)$.

The raw materials were analyzed for dry matter content, bulk density, effective heating value, ash, and total concentration of selected elements and easily available $\mathrm{N}$ (Table 1). The dry matter content was determined gravimetrically according to ISO 18134-1:2015. Samples of approximately $300 \mathrm{~g}$ of material were dried to constant weight at $105^{\circ} \mathrm{C}$. Bulk density was measured as in ISO 17828:2015, using a $30-\mathrm{L}$ container (height:diameter ratio 1.3). Heating value was analyzed according to SFS-EN 14,918 and total hydrogen $(\mathrm{H})$ concentration according to SFS-EN ISO 16948:2015. Ash content was determined thermogravimetrically $\left(550{ }^{\circ} \mathrm{C}, 5 \mathrm{~h}\right)$ and total carbon $(\mathrm{C})$ and $\mathrm{N}$ by dry combustion (LECO CN-2000). The total concentrations of other elements were analyzed by ICP-OES (Perkin Elmer Optima 8300) after aqua regia digestion, applying SFS-ISO 11466:2007. Easily available $\mathrm{N}$ [ammonium- $\mathrm{N}\left(\mathrm{NH}_{4}-\mathrm{N}\right)$, nitrate- $\mathrm{N}\left(\mathrm{NO}_{3}-\mathrm{N}\right)$, and total $\mathrm{N}$ after oxidative digestion] was analyzed in 1:60 (w/v) water extracts by a continuous flow analyzer (Skalar San ++ System).

\section{Laboratory Incubation}

The effect of spontaneous aerobic decomposition during storage on the final heating value was investigated under controlled laboratory conditions for: (i) $100 \%$ wood bark (B100), (ii) a mix of $75 \%$ wood bark and $25 \%$ wood pulp sludge (B75S25), and (iii) a mix of 50\% wood bark and $50 \%$ wood pulp sludge (B50S50). First, the bark and sludge reserved for the study were separately mixed and divided by repeated quartering into representative portions. The treatments were then established in 10-L containers, each in four replicates, by weighing the components in proportions of fresh mass to total $3.2 \mathrm{~kg}$ per container. In practice, each replicate was prepared by adding $8 \mathrm{~kg}$ of the desired biomass ( $8 \mathrm{~kg}$ bark $0 \mathrm{~kg}$ sludge; $6 \mathrm{~kg}$ bark, $2 \mathrm{~kg}$ sludge; $4 \mathrm{~kg}$ bark, $4 \mathrm{~kg}$ sludge) to a plastic basin and mixing thoroughly by hand. Thereafter, $3.2 \mathrm{~kg}$ were weighed into the experimental container and samples were taken from the remaining mass for analyses of dry matter content, effective heating value, ash and total concentrations of $\mathrm{C}$ and $\mathrm{H}$, which were conducted as for the raw materials (see Sect. "Raw materials"). The biomass added to the experimental containers was lightly compacted by allowing the containers to drop three times, under their own mass, from a height of $15 \mathrm{~cm}$.

In each container, two temperature sensors (ELOG 9004) were placed in the middle of the mass and set to record the temperature every four hours. Bi-metallic thermometers were also installed, to allow up-to-date monitoring. The 12 containers were placed in a completely randomized design in a temperature-controlled storage room, where they were kept in darkness at $19.5 \pm 1{ }^{\circ} \mathrm{C}$ for a total of 117 days. Loss of moisture during the incubation was roughly monitored by weighing the containers regularly. This follow-up did not indicate cessation of microbial activity due to lack of moisture, so no water was added. The duration of the incubation was chosen to correspond to the typical storage time at the industrial environment.
Table 1 Selected properties of wood pulp sludge and wood bark waste used in the laboratory and outdoor study

\begin{tabular}{clllll}
\hline & Sludge & Bark & & Sludge & Bark \\
\hline Initial dry matter (\%) & $35.0 \pm 0.0$ & $48.3 \pm 1.6$ & $\mathrm{Al}\left(\mathrm{g} \mathrm{kg}^{-1} \mathrm{dw}\right)$ & $12.3 \pm 0.21$ & $0.10 \pm 0.01$ \\
Bulk density $\left(\mathrm{kg} \mathrm{L}^{-1} \mathrm{fw}\right)$ & $0.52 \pm 0.01$ & $0.39 \pm 0.01$ & $\mathrm{~B}\left(\mathrm{mg} \mathrm{kg}^{-1} \mathrm{dw}\right)$ & $24.2 \pm 2.64$ & $22.8 \pm 5.12$ \\
Ash $(\%)$ & $12.0 \pm 0.1$ & $2.52 \pm 0.14$ & $\mathrm{Cu}\left(\mathrm{mg} \mathrm{kg}^{-1} \mathrm{dw}\right)$ & $8.93 \pm 0.06$ & $3.18 \pm 0.15$ \\
$\mathrm{C}(\%)$ & $44.8 \pm 0.4$ & $53.3 \pm 0.4$ & $\mathrm{Cd}\left(\mathrm{mg} \mathrm{kg}^{-1} \mathrm{dw}\right)$ & $0.31 \pm 0.01$ & $0.37 \pm 0.02$ \\
$\mathrm{~N}(\%)^{\mathrm{a}}$ & $1.13 \pm 0.01$ & $0.42 \pm 0.01$ & $\mathrm{Cr}\left(\mathrm{mg} \mathrm{kg}^{-1} \mathrm{dw}\right)$ & $6.50 \pm 0.61$ & $1.12 \pm 0.71$ \\
$\mathrm{P}\left(\mathrm{g} \mathrm{kg}^{-1} \mathrm{dw}\right)$ & $1.16 \pm 0.02$ & $0.32 \pm 0.02$ & $\mathrm{Fe}\left(\mathrm{g} \mathrm{kg}^{-1} \mathrm{dw}\right)$ & $3.10 \pm 0.05$ & $0.13 \pm 0.03$ \\
$\mathrm{~K}\left(\mathrm{~g} \mathrm{~kg}^{-1} \mathrm{dw}\right)$ & $0.38 \pm 0.02$ & $1.55 \pm 0.08$ & $\mathrm{Mn}\left(\mathrm{mg} \mathrm{kg}^{-1} \mathrm{dw}\right)$ & $1300 \pm 0.00$ & $403 \pm 37.8$ \\
$\mathrm{Ca}\left(\mathrm{g} \mathrm{kg}^{-1} \mathrm{dw}\right)$ & $13.1 \pm 0.15$ & $6.65 \pm 0.66$ & $\mathrm{Na}\left(\mathrm{g} \mathrm{kg}^{-1} \mathrm{dw}\right)$ & $1.87 \pm 0.06$ & $0.24 \pm 0.01$ \\
$\mathrm{Mg}\left(\mathrm{g} \mathrm{kg}^{-1} \mathrm{dw}\right)$ & $0.71 \pm 0.02$ & $0.60 \pm 0.03$ & $\mathrm{~Pb}\left(\mathrm{mg} \mathrm{kg}^{-1} \mathrm{dw}\right)$ & $<3.0$ & $<3.0$ \\
$\mathrm{~S}\left(\mathrm{~g} \mathrm{~kg}^{-1} \mathrm{dw}\right)$ & $5.00 \pm 0.11$ & $0.25 \pm 0.02$ & $\mathrm{Zn}\left(\mathrm{mg} \mathrm{kg}^{-1} \mathrm{dw}\right)$ & $36.0 \pm 1.73$ & $148 \pm 12.6$ \\
Heating value $(\mathrm{MJ} \mathrm{kg}$ & & & & \\
Calorific as dry & & & & $17.2 \pm 0.3$ & $20.6 \pm 0.3$ \\
Calorific as received & $6.4 \pm 0.2$ & $10.4 \pm 0.3$ & Effective as received & $4.4 \pm 0.1$ & $8.5 \pm 0.2$ \\
\hline
\end{tabular}

The values are mean of three (sludge) or four (bark) replicates \pm standard deviation. For the heating values, the expanded uncertainty of measurement is given (1.5\% as dry and $2.5 \%$ as received). The element concentrations are total values per unit dry weight $(\mathrm{dw})$

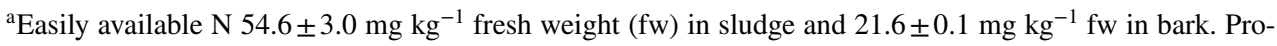
portion of organic $\mathrm{N} 99 \%$ in sludge, $95 \%$ in bark, $\mathrm{NO}_{3}-\mathrm{N} 1 \%$ in sludge, $5 \%$ in bark, no $\mathrm{NH}_{4}-\mathrm{N}$ detected 
Gaseous emissions of carbon dioxide $\left(\mathrm{CO}_{2}\right)$ were determined using the closed-chamber method with subsequent gas chromatography. Samples were taken 13 times during the incubation. On each occasion, the containers were closed with a lid for $5 \mathrm{~min}$, during which the headspace gases were sampled at one-minute intervals with a syringe. The gas samples were analyzed for $\mathrm{CO}_{2}$ concentration with an Agilent 7890 A gas chromatograph equipped with a Gilson autosampler. The results were calibrated against a calibration curve constructed based on a set of seven standards with increasing $\mathrm{CO}_{2}$ concentration $\left(\mathrm{R}^{2}\right.$ ranged between 0.97 and 1.00). The $\mathrm{CO}_{2}$ concentrations obtained were converted to mass according to the ideal gas law, taking into account the temperature and headspace volume of the container. Finally, the gas flux rate $\left(\mathrm{g} \mathrm{kg}^{-1} \mathrm{~h}^{-1}\right)$ was calculated from the increase in gas content over time, using linear regression.

At the end of the incubation, the containers were weighed. The biomass in each container was then separately emptied into a plastic basin, where it was thoroughly mixed by hand and sampled for analyses of dry matter content, effective heating value, ash, and total concentrations of $\mathrm{C}$ and $\mathrm{H}$. These laboratory analyses were carried out as described for the raw materials (see Sect. "Raw materials").

\section{Outdoor Storage}

In the outdoor storage study, the laboratory incubation setup (Sect. "Laboratory incubation") was implemented on a larger scale in a natural outdoor environment. The experiment was established on an open blacktop area at the Luke premises in Jokioinen in late April 2017. First, the wood bark and wood pulp sludge piles stored outdoors under plastic sheets (see Sect. "Raw materials") were thoroughly mixed using a tractor front loader and shovels. Both piles were then divided by repeated quartering into representative portions. Three treatments: (1) 100\% wood bark (B100), (2) a mix of $75 \%$ wood bark and $25 \%$ wood pulp sludge (B75S25), and (3) a mix of $50 \%$ wood bark $50 \%$ wood pulp sludge (B50S50), were constructed in $0.5 \mathrm{~m}^{3}$ plastic boxes, each covering an area of $1 \mathrm{~m}^{2}$, with three replicates. The components were weighed in proportions of fresh mass to give a total of $200 \mathrm{~kg}$ biomass per container. Due to differences in the inherent dry matter content and volume weight of the bark and sludge (Table 2), the volume and dry mass content differed somewhat between the treatments. The initial dry matter content was $51.5 \pm 2.2 \%$ in $\mathrm{B} 100,45.8 \pm 0.9 \%$ in B75S25, and $44.4 \pm 0.5 \%$ in B50S50 and consequently the dry mass content per container was $103 \pm 4,92 \pm 2$ and $89 \pm 1 \mathrm{~kg}$, respectively, in these treatments.
Table 2 Ash, total carbon $(\mathrm{C})$, and total hydrogen $(\mathrm{H})$ concentrations (\%) and effective heating value $\left(\mathrm{MJ} \mathrm{kg}^{-1}\right)$ as dry and as received (i.e., at inherent moisture content) of wood bark waste (B100) and bark-wood pulp sludge mixes (B25S75, B75S25) before and after storage under laboratory (18 weeks) and outdoor (26 weeks) conditions

\begin{tabular}{llllll}
\hline & \multicolumn{2}{l}{ Laboratory storage } & & \multicolumn{2}{l}{ Outdoor storage } \\
\cline { 2 - 3 } \cline { 5 - 6 } & Initial value & Post-storage value & & Initial value & Post-storage value \\
\hline Ash (\%) & & & & \\
B100 & $2.55 \pm 0.13^{\mathrm{a}}$ & $2.94 \pm 0.23^{\mathrm{a}}$ & & $2.27 \pm 0.19^{\mathrm{a}}$ & $2.59 \pm 0.19^{\mathrm{a}}$ \\
B75S25 & $4.14 \pm 0.13^{\mathrm{b}}$ & $5.56 \pm 0.23^{\mathrm{d}}$ & & $5.06 \pm 0.19^{\mathrm{b}}$ & $5.78 \pm 0.19^{\mathrm{b}}$ \\
B50S50 & $6.81 \pm 0.13^{\mathrm{c}}$ & $8.10 \pm 0.23^{\mathrm{e}}$ & & $7.66 \pm 0.19^{\mathrm{c}}$ & $9.82 \pm 0.19^{\mathrm{d}}$ \\
Total C $(\%)$ & & & & \\
B100 & $53.32 \pm 0.32^{\mathrm{a}}$ & $53.36 \pm 0.32^{\mathrm{a}}$ & & $54.85 \pm 0.46^{\mathrm{a}}$ & $54.49 \pm 0.28^{\mathrm{a}}$ \\
B75S25 & $51.83 \pm 0.32^{\mathrm{b}}$ & $52.05 \pm 0.32^{\mathrm{b}}$ & & $52.17 \pm 0.46^{\mathrm{b}}$ & $53.64 \pm 0.28^{\mathrm{a}, \mathrm{b}}$ \\
B50S50 & $49.39 \pm 0.32^{\mathrm{c}}$ & $50.21 \pm 0.32^{\mathrm{c}}$ & & $50.57 \pm 0.46^{\mathrm{b}, \mathrm{c}}$ & $50.89 \pm 0.28^{\mathrm{c}}$ \\
Total H (\%) & & & & \\
B100 & $6.34 \pm 0.04^{\mathrm{a}}$ & $6.09 \pm 0.04^{\mathrm{c}}$ & & $6.45 \pm 0.10^{\mathrm{a}}$ & $6.02 \pm 0.04^{\mathrm{b}}$ \\
B75S25 & $6.22 \pm 0.04^{\mathrm{a}}$ & $5.80 \pm 0.04^{\mathrm{d}}$ & & $6.09 \pm 0.10^{\mathrm{a}}$ & $5.77 \pm 0.04^{\mathrm{a}}$ \\
B50S50 & $6.06 \pm 0.04^{\mathrm{b}}$ & $5.61 \pm 0.04^{\mathrm{e}}$ & & $6.10 \pm 0.10^{\mathrm{a}}$ & $5.56 \pm 0.04^{\mathrm{c}}$ \\
Effective heating value, dry $\left(\mathrm{MJ} \mathrm{kg}^{-1}\right)$ & & & & \\
B100 & $20.6 \pm 0.18^{\mathrm{a}}$ & $19.5 \pm 0.05^{\mathrm{c}}$ & & $21.2 \pm 0.38^{\mathrm{a}}$ & $19.8 \pm 0.13^{\mathrm{a}}$ \\
B75S25 & $20.2 \pm 0.18^{\mathrm{a}}$ & $19.2 \pm 0.05^{\mathrm{d}}$ & & $20.0 \pm 0.38^{\mathrm{a}}$ & $19.4 \pm 0.13^{\mathrm{a}, \mathrm{b}}$ \\
B50S50 & $19.4 \pm 0.18^{\mathrm{b}}$ & $18.7 \pm 0.05^{\mathrm{e}}$ & & $19.8 \pm 0.38^{\mathrm{a}, \mathrm{b}}$ & $18.9 \pm 0.13^{\mathrm{b}}$ \\
Effective heating value, as received $\left(\mathrm{MJ} \mathrm{kg}{ }^{-1}\right)$ & & & \\
B100 & $8.5 \pm 0.14^{\mathrm{a}}$ & $12.4 \pm 0.24^{\mathrm{d}}$ & & $9.2 \pm 0.28^{\mathrm{a}}$ & $4.1 \pm 0.05^{\mathrm{d}}$ \\
B75S25 & $7.5 \pm 0.14^{\mathrm{b}}$ & $11.4 \pm 0.24^{\mathrm{e}}$ & & $7.3 \pm 0.28^{\mathrm{b}}$ & $3.5 \pm 0.05^{\mathrm{e}}$ \\
B50S50 & $6.5 \pm 0.14^{\mathrm{c}}$ & $10.8 \pm 0.24^{\mathrm{e}}$ & & $6.0 \pm 0.28^{\mathrm{c}}$ & $2.7 \pm 0.05^{\mathrm{f}}$ \\
\hline
\end{tabular}

The values shown are mean of four (laboratory study) or three (outdoor study) replicates \pm standard error. Values with different letters within columns and within rows for each experiment are statistically significant at $\mathrm{p}<0.05$ (cross-wise comparisons were not made) 
The heaps containing both bark and sludge were thoroughly mixed with shovels before adding the biomass to the storage boxes. Representative samples for laboratory analyses were collected while filling each box. These samples were analyzed for dry matter content, effective heating value, ash, and total concentration of $\mathrm{C}, \mathrm{H}, \mathrm{N}$, aluminum $(\mathrm{Al})$, boron $(\mathrm{B})$, calcium $(\mathrm{Ca})$, copper $(\mathrm{Cu})$, cadmium $(\mathrm{Cd})$, chromium $(\mathrm{Cr})$, iron $(\mathrm{Fe})$, potassium $(\mathrm{K})$, magnesium $(\mathrm{Mg})$, manganese $(\mathrm{Mn})$, sodium $(\mathrm{Na})$, phosphorus $(\mathrm{P})$, lead $(\mathrm{Pb})$, sulfur $(\mathrm{S})$, and zinc $(\mathrm{Zn})$, as described in Sect. "Raw materials". In addition, $\mathrm{pH}$ was analyzed in a 1:5 biomass:water suspension (EN 13,037).

Two temperature sensors were placed in the middle of the biomass in each storage box, to record the temperature every four hours. Two additional temperature sensors were placed between the boxes in shade, to monitor the temperature of the ambient air. The boxes were arranged in a completely randomized block design and positioned to have a 5\% slope towards the bottom drainage outlet. The leachate was collected in plastic containers, weighed, and sampled for analysis of $\mathrm{NH}_{4}-\mathrm{N}$ (SFS 3032), $\mathrm{NO}_{3}-\mathrm{N}$ (SFS 3030), total N (SFS 3031), phosphate-P ( $\left.\mathrm{PO}_{4}-\mathrm{P}\right)$ (SFS 3025), total P (SFS 3026), dissolved solids (SFS 3008), chemical oxygen demand (COD_Cr) (SFS 5504), and total concentrations of $\mathrm{Al}, \mathrm{B}, \mathrm{Ca}, \mathrm{Cu}, \mathrm{Cd}, \mathrm{Cr}, \mathrm{Fe}, \mathrm{K}, \mathrm{Mg}, \mathrm{Mn}$, $\mathrm{Na}, \mathrm{Pb}, \mathrm{S}$, and $\mathrm{Zn}$, which were analyzed in filtered samples by ICP-OES (Perkin Elmer Optima 8300). Weather data were acquired from the meteorological station in Jokioinen, located approximately $1 \mathrm{~km}$ from the study site.

Gaseous emissions of $\mathrm{CO}_{2}, \mathrm{CH}_{4}$, and $\mathrm{N}_{2} \mathrm{O}$ were determined on 18 occasions during the storage period, using the closed chamber method with subsequent gas chromatography analysis. In the beginning of the experiment, a $60 \mathrm{~cm} \times 60 \mathrm{~cm}$ collar was permanently installed on top of the material in each container. During the measurements of gaseous emissions, a metal chamber measuring $60 \mathrm{~cm} \times$ $60 \mathrm{~cm} \times 20 \mathrm{~cm}$ was placed on the top of the collar and gas samples were extracted 3, 6, 9, and 12 min after closing the chamber. Ammonia $\left(\mathrm{NH}_{3}\right)$ emissions were measured three times during the 6-month storage period, using the same metal chambers. For the $\mathrm{NH}_{3}$ analysis, the chambers were closed for approximately $10 \mathrm{~min}$, during which the air inside the chambers was circulated through a photoacoustic gas analyzer (INNOVA AirTech Instruments 1412), which measured the $\mathrm{NH}_{3}$ concentration at 2-min intervals. Gas flux rates $\left(\mathrm{g} \mathrm{kg}^{-1} \mathrm{~h}^{-1}\right)$ were calculated as described in the Sect. "Laboratory incubation".

The containers were weighed after 26 weeks of undisturbed storage. Immediately thereafter, the biomass was sampled for laboratory analyses of dry matter content, effective heating value, ash, and total concentrations of $\mathrm{C}$ and $\mathrm{H}$ (see Sect. "Raw materials"). To ensure a representative sample, the contents of each container were emptied separately onto a clean surface and thoroughly mixed with shovels.

\section{Statistical Analysis}

The experimental design was a randomized complete block design (RCBD) with three replicates in the outdoor experiment and a completely randomized design with four replicates in the laboratory experiment. Linear mixed models with treatment (B100, B75S25, B50S50) and time point (initial/poststorage), and their interaction, were denoted as fixed effects. The replicates were assumed to be independent and normally distributed random effects. Correlation between time points was taken into account using a heterogeneous or homogeneous compound symmetry (CSH and CS) covariance structure [17]. The homogeneity of treatment variances was tested, and rejected when necessary, by using a likelihood ratio test.

The relationship between biomass temperature and ambient air temperature in the outdoor study was analyzed with repeated measures analysis of covariance (ANCOVA), using treatment and air temperature as fixed effects. Differences between treatment means were tested at different temperature points. ANCOVA was used also for $\mathrm{CO}_{2}$ emissions having treatment as a categorical, and temperature and time points as continuous fixed effects. All interactions were included, and heterogeneous variances of treatments were allowed in both models. Analysis of variance (ANOVA) was used for $\mathrm{CO}_{2}$ emissions in the laboratory experiment having treatment and time, and their interaction, as fixed effects. Cumulative emissions of $\mathrm{CO}_{2}, \mathrm{~N}_{2} \mathrm{O}, \mathrm{CH}_{4}$ and $\mathrm{NH}_{3}$ were analyzed as a $\mathrm{RCBD}$ with three replicates.

The distributions of $\mathrm{CO}_{2}$ emissions were skewed to the right. Thus, gamma (with log link) and lognormal (with identity link) distributions were used for laboratory and outdoor analysis, respectively. The first was fitted using the residual pseudo-likelihood (REPL) estimation method, while all other models were fitted using the residual maximum likelihood (REML). The residuals were checked for normality using boxplot and plotted against the fitted values. The method of Westfall was used for all interesting pairwise comparisons of means [18]. A significance level of $\alpha=0.05$ was used in all analyses. Degrees of freedom were calculated using the Kenward-Roger method [19]. All analyses were performed using the GLIMMIX procedure in the SAS Enterprise Guide 7.1 (SAS Institute Inc., Cary, NC, USA). 


\section{Results}

\section{Degradation of Biomass During Storage}

\section{Temperature Profiles}

During laboratory incubation study, no marked rise in temperature was observed in the pure bark or the bark-sludge mixes (Fig. 1). In all treatments, the biomass temperature peaked at $22-23{ }^{\circ} \mathrm{C}$ immediately after the start of incubation. In the bark-sludge mixes, another temperature peak occurred around 17 days from the start of incubation and mean daily temperature remained slightly higher than that in the pure bark until 55 days from the start of incubation. Thereafter, the temperature in all biomasses equaled the ambient air temperature.

In the outdoor storage study, the temperature in the biomass piles was found to follow the temperature of the ambient air, but was mainly on a slightly higher level (Fig. 2a). The treatments were found to respond differently to changes in the ambient temperature, with the treatments containing sludge exhibiting higher temperatures than those containing only pure bark at ambient temperatures exceeding $5{ }^{\circ} \mathrm{C}$ (Fig. 2b). At ambient air temperatures exceeding $10^{\circ} \mathrm{C}$, the temperature in all treatments differed significantly from each other, with B100 exhibiting the lowest and B75S25 the highest temperature in relation to the ambient air temperature.

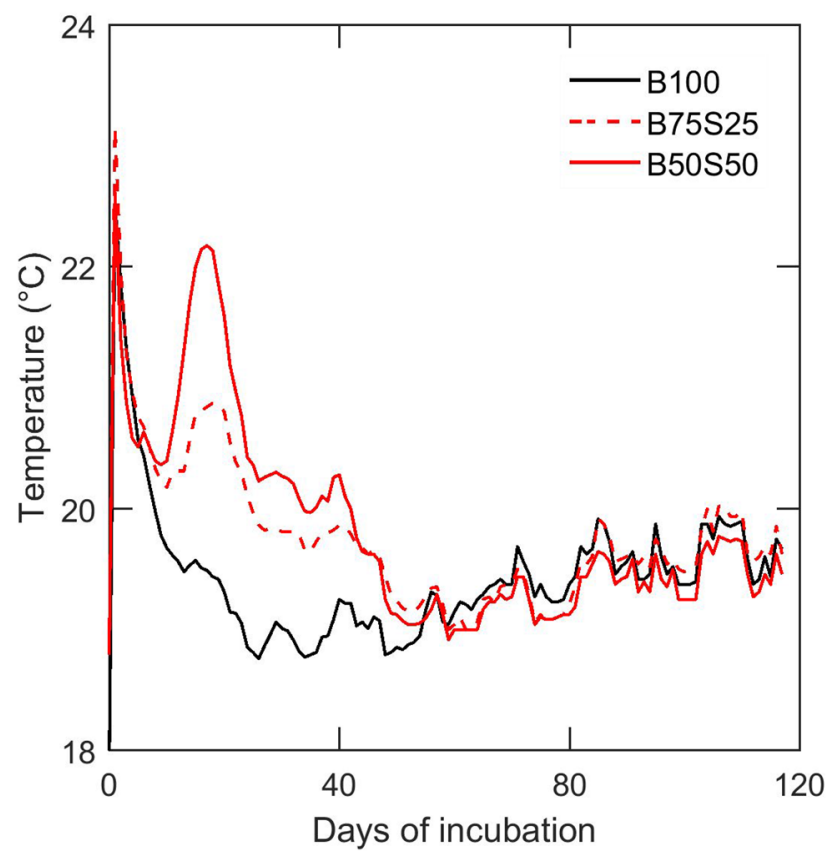

Fig. 1 Mean daily temperature $\left({ }^{\circ} \mathrm{C}\right)$ inside 10-L containers of wood bark waste (B100) and bark-wood pulp sludge mixes (B25S75, B75S25). The values shown are mean of four replicates
The maximum mean daily temperature reached during outdoor storage was $28{ }^{\circ} \mathrm{C}$ in the bark-sludge (B75S25 and B50S50) treatments and $21^{\circ} \mathrm{C}$ in the bark-only treatment (B100), whereas the highest mean daily air temperature was $19{ }^{\circ} \mathrm{C}$.

\section{Emissions of $\mathrm{CO}_{2}$}

In the laboratory incubation, emissions of $\mathrm{CO}_{2}$ tended to be highest in the beginning of the experiment (Fig. 3). Emissions then generally decreased over time, although the barksludge mixes showed a temporal increase in $\mathrm{CO}_{2}$ production after about 2 weeks of incubation. Regarding $\mathrm{CO}_{2}$ production, all treatments deviated significantly $(\mathrm{p}<0.001)$ from each other between 14 and 34 days from the beginning of the incubation, during which period the highest emissions were recorded for B50S50 and the lowest for B100. At day 42 of incubation, $\mathrm{CO}_{2}$ emissions from the B75S25 and B50S50 treatments were higher than those from B100. In the beginning (until day 7) and end (after day 60) of the incubation, there were no statistically significant differences in $\mathrm{CO}_{2}$ emission rates between the treatments.

In the outdoor study, $\mathrm{CO}_{2}$ emissions were highest during late summer, from July to September (Fig. 4). The lowest emissions were observed in May and late October. Throughout the study period, both sludge-containing treatments (B75S25 and B50S50) produced significantly higher $\mathrm{CO}_{2}$ emissions than B100. Until late July, B50S50 emitted significantly more $\mathrm{CO}_{2}$ than B75S25. In September, however, B75S25 showed significantly higher $\mathrm{CO}_{2}$ emissions than B50S50. The $\mathrm{CO}_{2}$ emission rates were found to be correlated with ambient air temperature, with the correlation being strongest for B50S50 $(r=0.78)$, followed by B75S25 $(\mathrm{r}=0.69)$ and $\mathrm{B} 100(\mathrm{r}=0.61)$. The correlation between $\mathrm{CO}_{2}$ emissions and rainfall was weak $(r=0.08)$.

\section{Loss of Dry Mass During Storage}

The total dry mass content of all bark and bark-sludge mixes studied decreased during storage under both laboratory and outdoor conditions. In the laboratory study, the biomass loss was lowest in the B100 treatment, on average 8.1\% [standard error $(\mathrm{SE})=1.0$ ] of its initial dry matter content, whereas the bark-sludge mixes lost on average $12.7 \%(\mathrm{~B} 75 \mathrm{~S} 25, \mathrm{SE}=1.8)$ and $14.4 \%(\mathrm{~B} 50 \mathrm{~S} 50, \mathrm{SE}=1.3)$ of their initial dry matter. The difference in proportion of dry matter lost was significant between the B100 and B50S50 treatments $(p=0.031)$ and almost significant between the B100 and B75S25 treatments $(p=0.083)$.

The dry mass losses in the outdoor storage experiment displayed a similar pattern. The lowest biomass loss was in B100 (16.2\%, SE = 5.3), followed by B75S25 (25.1\%, $\mathrm{SE}=1.2)$ and $\mathrm{B} 50 \mathrm{~S} 50(28.8 \%, \mathrm{SE}=0.5)$. However, the 
Fig. 2 a Mean daily temperature $\left({ }^{\circ} \mathrm{C}\right)$ inside $0.5 \mathrm{~m}^{3}$ containers of wood bark waste (B100) and bark-wood pulp sludge mixes (B25S75, B75S25) and ambient air temperature during 26 weeks of storage outdoors; and b relationship between biomass temperature and ambient air temperature. The difference between B100 and B50S50 was statistically significant at ambient air temperature $>3{ }^{\circ} \mathrm{C}$ $(\mathrm{p}=0.047)$, that between B100 and $\mathrm{B} 75 \mathrm{~S} 25$ at ambient air temperature $>5{ }^{\circ} \mathrm{C}(\mathrm{p}=0.008)$ and that between B50S50 and B75S25 at ambient air temperature $10{ }^{\circ} \mathrm{C}(\mathrm{p}=0.043)$. The values shown are mean of three replicates
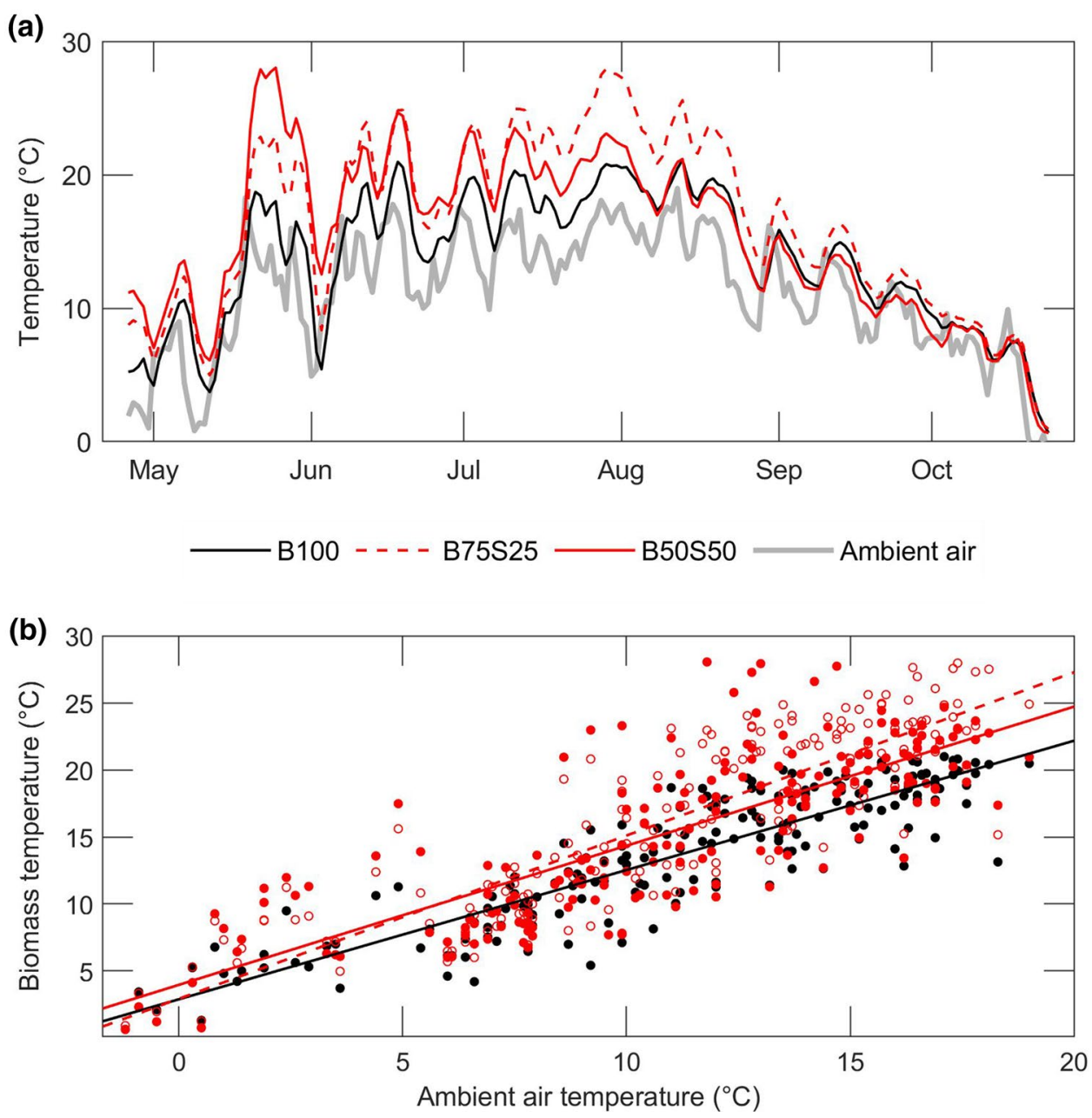

differences between treatments were not statistically significant. An exceptionally high percentage dry matter loss was recorded for the third replicate of the B100 treatment and, since an error in weighing that box was suspected, the data were also analyzed without the deviating value. The biomass loss from $\mathrm{B} 100$ then fell to $11.3 \%(\mathrm{SE}=3.1)$, but the differences between the treatments were still not significant $(\mathrm{p}=0.161)$.

Mean monthly dry mass loss in B100, B75S25, and B25S75 was 2.1, 3.3, and 3.7\%, respectively, in the laboratory study, and $2.7,4.2$ and $4.8 \%$, respectively, in the outdoor study.

\section{Biomass Heating Value}

The ash content of the biomass samples increased as the proportion of sludge increased (Table 2). Storage tended to increase the ash concentration further, and thus total C and total $\mathrm{H}$ concentrations decreased as the proportion of sludge to bark increased. The effect of storage on total C was insignificant, but total $\mathrm{H}$ concentration of the biomasses decreased during the experiment.
The effective heating value of dry sludge was roughly $3.5 \mathrm{MJ} \mathrm{kg}^{-1}$ lower than that of the bark (Table 1), and consequently the pre-storage (initial) effective heating value of B50S50 was found to be significantly lower than that of $\mathrm{B} 100$ and B75S25 in the laboratory study (Table 2). On a fresh mass basis, the effective heating value decreased as the proportion of sludge to bark increased. During storage, the heating value of the dry biomass decreased by roughly $1 \mathrm{MJ}$ $\mathrm{kg}^{-1}$ in all treatments, but these within treatments reductions were significant only in the laboratory experiment. However, in the outdoor study the post-storage effective heating value 'as dry' was significantly lower in the B50S50 treatment than in the B100 treatment. In the laboratory incubation, these post-storage values for all treatments differed from each other. In practice, the moisture content of the biomass governed its heating value. In the laboratory incubation conducted without water addition, the dry matter concentration of the biomasses increased with time from the initial $48 \%$ in $\mathrm{B} 100,45 \%$ in $\mathrm{B} 75 \mathrm{~S} 25$, and $42 \%$ in $\mathrm{B} 50 \mathrm{~S} 50$ to 71,68 , and $65 \%$, respectively. In contrast, in the outdoor storage study the biomasses were wetted from the initial dry matter concentration of $51 \%$ in B100, $46 \%$ in B 75 S25, and $44 \%$ in 


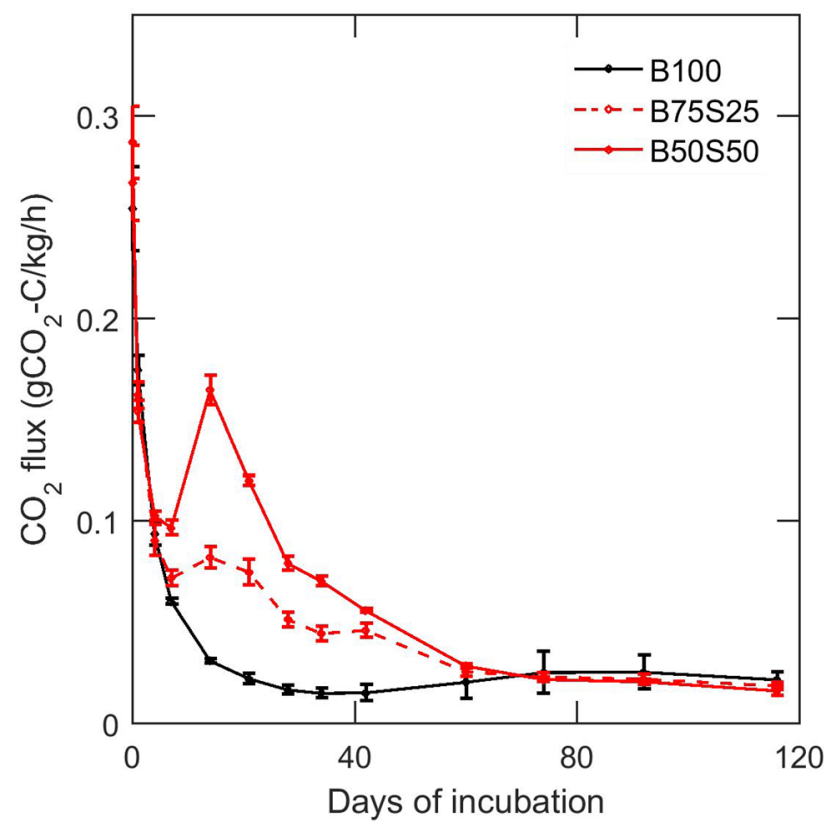

Fig. 3 Mean carbon dioxide $\left(\mathrm{CO}_{2}\right)$ emissions from wood bark waste (B100) and bark-wood pulp sludge mixes (B25S75, B75S25) during 117 days of laboratory incubation at $19.5 \pm 1.0^{\circ} \mathrm{C}$. The error bars denote standard deviation, $\mathrm{n}=4$

B50S50 to 30, 28, and 27\%, respectively. Consequently, in the laboratory study the effective heating value 'as received' increased, while in the outdoor study it decreased during storage. The post-storage heating values were significantly lower in the bark-sludge mixes than in pure bark in both the indoor and outdoor experiments.

When estimating the storage-induced total losses of energy during the test period, both the loss of heating value and the loss of biomass (see Sect. "Loss of dry mass during storage") need to be accounted for. In the case of B100 in the controlled laboratory environment, the total loss of energy content was $13.0 \%$, calculated as effective heat value 'as dry', while in $\mathrm{B} 75 \mathrm{~S} 25$ it was $17.0 \%$ and in B50S50 17.5\%. The energy value loss in the outdoor study was $21.7 \%$ for $\mathrm{B} 100,27.3 \%$ for $\mathrm{B} 75 \mathrm{~S} 25$, and $32.0 \%$ for B50S50. These results indicate that loss of total energy was larger in biomasses where sludge was present. In practice, however, the moisture content of the fuels still dominated the real effective heating value.

\section{Environmental Impacts}

\section{Greenhouse Gas Emissions}

Cumulative $\mathrm{CO}_{2}$ emissions depended on the treatment $(p<0.001)$ and were over five times higher in the sludgecontaining treatments (B75S25 and B50S50) than in B100 (Table 3). The cumulative $\mathrm{CH}_{4}$ emissions were also higher in sludge-containing treatments than in $\mathrm{B} 100$. The treatments did not deviate from each other $(\mathrm{p}=0.69)$ in terms of $\mathrm{N}_{2} \mathrm{O}$ fluxes. All treatments ended up acting as a small sink, rather than a source, of $\mathrm{N}_{2} \mathrm{O}$. Likewise, the $\mathrm{NH}_{3}$ emissions were negligible overall.

Table 3 Cumulative sum of carbon dioxide $\left(\mathrm{CO}_{2}\right)$, nitrous oxide $\left(\mathrm{N}_{2} \mathrm{O}\right)$, methane $\left(\mathrm{CH}_{4}\right)$, and ammonia $\left(\mathrm{NH}_{3}\right)$ emissions from wood bark waste (B100) and bark-wood pulp sludge mixes (B25S75, B75S25) during the outdoor experiment

\begin{tabular}{lllll}
\hline & \multicolumn{4}{l}{ Cumulative emissions $\left(\mathrm{g} \mathrm{kg}^{-1}\right)$} \\
\cline { 2 - 5 } & $\mathrm{CO}_{2}$ & $\mathrm{~N}_{2} \mathrm{O}$ & $\mathrm{CH}_{4}$ & $\mathrm{NH}_{3}$ \\
\hline B100 & $19.0^{\mathrm{a}}$ & $-0.037^{\mathrm{a}}$ & $0.006^{\mathrm{a}}$ & $0.005^{\mathrm{a}}$ \\
B75S25 & $100.5^{\mathrm{b}}$ & $-0.049^{\mathrm{a}}$ & $0.113^{\mathrm{b}}$ & $0.008^{\mathrm{a}}$ \\
B50S50 & $126.7^{\mathrm{c}}$ & $-0.056^{\mathrm{a}}$ & $0.054^{\mathrm{b}}$ & $0.003^{\mathrm{a}}$ \\
\hline
\end{tabular}

$\mathrm{N}_{2} \mathrm{O}$ and $\mathrm{CH}_{4}$ emissions are expressed as $\mathrm{CO}_{2}$-equivalents. Values with different letters within columns are significantly different at $\mathrm{p}<0.05$
Fig. 4 (Left) Mean carbon dioxide $\left(\mathrm{CO}_{2}\right)$ emissions from wood bark waste (B100) and bark-wood pulp sludge mixes (B25S75, B75S25); and (right) weekly rainfall and mean temperature during 6 months of storage outdoors (May-October). Error bars denote standard deviation, $\mathrm{n}=3$
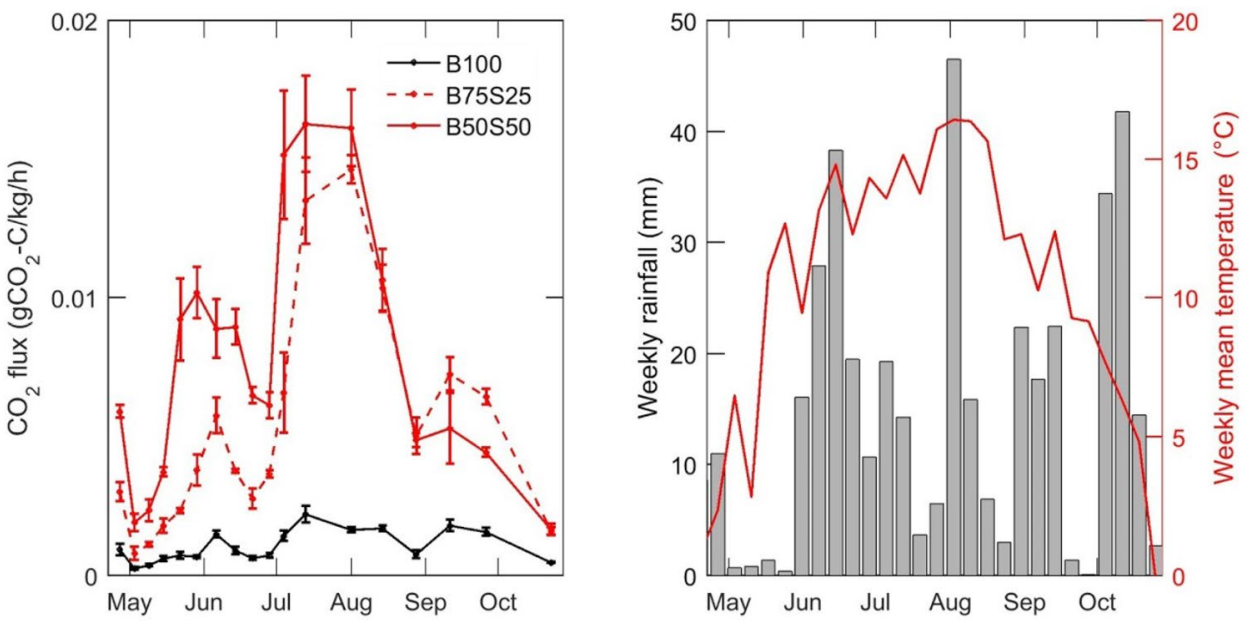


\section{Loss of Elements via Leaching}

Cumulative precipitation in the study area during the outdoor experiment (April 26-October 23) was $394.5 \mathrm{~mm}$, according to data from Jokioinen meteorological station. Samples of leachate were collected on a total of 18 occasions, with sample size varying between 1.5 and $25 \mathrm{~L}$. The highest amount of leachate $(238 \pm 4 \mathrm{~L})$ was obtained from B50S50, followed by B75S25 (226 $\pm 2 \mathrm{~L})$ and B100 $(192 \pm 2 \mathrm{~L})$.

The cumulative amount of solids leached in percolating water corresponded to less than $0.5 \%$ of the total initial dry mass in the treatments. The greatest amount of solids $\left(4.76 \pm 0.07 \mathrm{~g} \mathrm{~kg}^{-1}\right.$ initial biomass dry matter) was leached from B50S50, followed by B100 (4.26 $\mathrm{g} \pm 0.10)$ and B75S25 $(2.99 \pm 0.02)$. Total COD over the study period was significantly higher in B100 than in the sludge-containing treatments $\left(5241,2714\right.$, and $2723 \mathrm{mg} \mathrm{kg}^{-1}$ of initial dry biomass in B100, B75S25, and B50S50, respectively, SE $=138$ ).

Apart from $P$, the amounts of nutrients and harmful metals leached with percolating water tended to be lower from B100 than from the sludge-containing treatments B75S25 and B50S50 (Table 4). In general, the amount of elements leached increased with increasing proportion of sludge. There was no significant difference between the B75S25 and B50S50 treatments in terms of amount of $\mathrm{P}, \mathrm{Al}, \mathrm{Fe}$,

Table 4 Cumulative amount of different elements leached from wood bark waste (B100) and bark-wood pulp sludge mixes (B25S751, B75S25) during 26 weeks of storage outdoors

\begin{tabular}{llll}
\hline & \multicolumn{2}{l}{$\begin{array}{l}\text { Amount of element leached }\left(\mathrm{mg} \mathrm{kg}^{-1} \mathrm{DM} \text { of initial }\right. \\
\text { biomass })\end{array}$} \\
\cline { 2 - 4 } & B100 & B75S25 & B50S50 \\
\hline $\mathrm{N}$ & $10.09 \pm 0.75^{\mathrm{a}}$ & $21.01 \pm 0.75^{\mathrm{b}}$ & $28.75 \pm 0.75^{\mathrm{c}}$ \\
$\mathrm{P}$ & $34.27 \pm 1.37^{\mathrm{a}}$ & $1.98 \pm 0.17^{\mathrm{b}}$ & $2.43 \pm 0.12^{\mathrm{b}}$ \\
$\mathrm{Al}$ & $0.13 \pm 0.01^{\mathrm{a}}$ & $1.59 \pm 0.10^{\mathrm{b}}$ & $1.54 \pm 0.10^{\mathrm{b}}$ \\
$\mathrm{B}$ & $0.02 \pm 0.004^{\mathrm{a}}$ & $0.08 \pm 0.004^{\mathrm{b}}$ & $0.05 \pm 0.004^{\mathrm{c}}$ \\
$\mathrm{Ca}$ & $7.9 \pm 4.97^{\mathrm{a}}$ & $73.5 \pm 4.97^{\mathrm{b}}$ & $154.9 \pm 4.97^{\mathrm{c}}$ \\
$\mathrm{Cd}$ & $\mathrm{nd}$ & $\mathrm{nd}$ & $\mathrm{nd}$ \\
$\mathrm{Cr}$ & $\mathrm{nd}$ & $\mathrm{nd}$ & $\mathrm{nd}$ \\
$\mathrm{Cu}$ & $0.02 \pm 0.02^{\mathrm{a}}$ & $0.19 \pm 0.02^{\mathrm{b}}$ & $0.06 \pm 0.02^{\mathrm{a}}$ \\
$\mathrm{Fe}$ & $0.02 \pm 0.006^{\mathrm{a}}$ & $0.77 \pm 0.057^{\mathrm{b}}$ & $0.73 \pm 0.061^{\mathrm{b}}$ \\
$\mathrm{K}$ & $49.6 \pm 3.43^{\mathrm{a}}$ & $237.2 \pm 3.43^{\mathrm{b}}$ & $280.6 \pm 3.43^{\mathrm{c}}$ \\
$\mathrm{Mg}$ & $2.57 \pm 0.16^{\mathrm{a}}$ & $15.14 \pm 0.52^{\mathrm{b}}$ & $39.4 \pm 0.81^{\mathrm{c}}$ \\
$\mathrm{Mn}$ & $0.71 \pm 0.002^{\mathrm{a}}$ & $1.11 \pm 0.299^{\mathrm{a}}$ & $0.94 \pm 0.035^{\mathrm{a}}$ \\
$\mathrm{Na}$ & $11.97 \pm 4.58^{\mathrm{a}}$ & $207.4 \pm 4.58^{\mathrm{b}}$ & $566.2 \pm 4.58^{\mathrm{c}}$ \\
$\mathrm{Pb}$ & $\mathrm{nd}$ & nd & nd \\
$\mathrm{S}$ & $0.03 \pm 6.31^{\mathrm{a}}$ & $39.4 \pm 6.31^{\mathrm{b}}$ & $250.9 \pm 6.31^{\mathrm{c}}$ \\
$\mathrm{Zn}$ & $0.20 \pm 0.02^{\mathrm{a}}$ & $0.32 \pm 0.02^{\mathrm{b}}$ & $0.29 \pm 0.02^{\mathrm{b}}$ \\
\hline
\end{tabular}

Values with different letters within rows are significantly different at $\mathrm{p}<0.05$

$n d$ not detected and $\mathrm{Mn}$ in leachate, but the amount of $\mathrm{B}$ and $\mathrm{Cu}$ in leachate was higher from B75S25 than from B50S50. For P, the amount leached in percolating waters during the experiment was roughly 15 times higher in B100 than in the sludgecontaining treatments. In the leachate from B100, 15 $\pm 5 \%$ of the $\mathrm{P}$ found was in organic form, whereas in the leachate from B75S25 and B50S50 the corresponding proportion was $85 \pm 13$ and $93 \pm 9 \%$, respectively. The $\mathrm{N}$ leached was mainly (94-99\%) organically bound in all treatments.

The cumulative amount of $\mathrm{N}, \mathrm{Al}, \mathrm{B}, \mathrm{Fe}, \mathrm{Mn}$, and $\mathrm{Zn}$ leached corresponded to less than $0.5 \%$ of the total content of the elements in the initial biomass. For $\mathrm{Ca}, \mathrm{Cu}$, and $\mathrm{Mg}$, the corresponding proportions tended to be slightly higher but still less than 5\%. In the sludge-containing treatments, $\mathrm{K}, \mathrm{Na}$, and $\mathrm{S}$ were somewhat more mobile, with the amount leached in percolating water corresponding to 18 and $25 \%$ of initial K, 32 and $49 \%$ of initial $\mathrm{Na}$, and 3 and $9 \%$ of initial S in the B75S25 and B50S50 treatment, respectively. In B100, $10 \%$ of the initial $\mathrm{P}$ content in the biomass was recovered in the leachate, whereas for the sludge-containing treatments the corresponding proportion was $0.3 \%$.

\section{Discussion}

In the present analysis, biological degradation of wood pulp waste biomass during storage was assessed directly as dry matter loss and indirectly via $\mathrm{CO}_{2}$ emission rate and heat formation, i.e., microbial respiration and heat release. All these measures indicated that biological decomposition activity was higher in the mixed bark-sludge biomasses (B75S25 and B50S50) than in the pure bark material (B100). Increasing the proportion of sludge in the mixture from 25 to $50 \%$ (fresh weight) increased heat release and cumulative $\mathrm{CO}_{2}$ emissions. However, the biological activity in B50S50 seemed to be higher mainly in the early part of the storage period, whereas that in B75S25 exhibited higher activity towards the end. It can be assumed that the increased degradation activity in the mixed biomass not only reflected the higher degradation potential of the sludge (caused by higher $\mathrm{N}$ and moisture content and smaller particle size in comparison with bark), but also led to enhanced decomposition of the bark material.

Mean dry mass losses per month were similar in the laboratory and outdoor experiments, although the rates were slightly lower in the laboratory. Lower than optimal moisture content for microbial activity in the drying surface layer of the biomasses stored indoors may have contributed to this difference. The accuracy of dry mass loss determination was challenged in general by the inherent non-homogeneity of the material, namely in relation to moisture distribution, and consequently the differences between treatments were not statistically significant in the outdoor experiment. Previous studies on 
degradation of bark are scarce. Ernstson et al. [20] incubated spruce bark at different temperatures and atmospheres, and found that dry mass loss rates calculated from oxygen consumption ranged from $1.5 \%$ to nearly $20 \%$ per month. Studies on variously stored logging residues have reported monthly dry mass loss rates varying mainly from below 1-3\% [21-23].

As the ambient temperature and $\mathrm{CO}_{2}$ profiles revealed, the degradation activity was not linear in time. Rather, an initial activity peak, likely caused by consumption of the most easily digestible materials, was followed by ambient temperaturedependent fluctuations. Wood waste piles are known to selfheat, even to the point of spontaneous ignition [24, 25], but in small piles there is usually no marked temperature rise [26]. Conditions in the small piles stored at temperatures below $30{ }^{\circ} \mathrm{C}$ throughout the present study can be taken to represent those in the outer layers of the large waste stacks at pulp mills, which do not exhibit the thermo-chemical oxidative reactions occurring at higher temperatures [6]. For biological decomposition, however, moderate temperature levels $\left(25-40{ }^{\circ} \mathrm{C}\right)$ are favorable [20, 27, 28]. Below the optimum temperature, biological decomposition progressively decreases $[29,30]$. In the present study, differences in heat release between treatments decreased with decreasing ambient air temperature, but the increase in biological activity caused by the higher sludge inclusion (B50S50) was discernible already at an ambient temperature of $3{ }^{\circ} \mathrm{C}$. In the climate at high latitudes, sludge addition to bark may thus extend the period of active decomposition compared with that of pure bark. More detailed analysis of the microbial community and its functioning in different sludges is recommended for future studies.

In addition to temperature, biological decomposition rate depends on moisture. At very low water potential (around $-40 \mathrm{MPa}$ ) degradation will cease, whereas with increasing moisture the decomposition activity tends to increase until the rate of oxygen diffusion becomes limiting $[29,30]$. There was no correlation between $\mathrm{CO}_{2}$ emissions and rainfall during outdoor storage in the present study, indicating minor moisture-related limitations. However, as stated earlier, in the laboratory incubation with no external water input, a moisture gradient developed from the bottom of the container to the surface, and degradation in upper layers may have been retarded by low moisture content.

The contrasting trends in biomass moisture status from start to end of the experiment between the laboratory (moisture decrease) and outdoor study (moisture increase) governed the final effective heating value of the biomasses. The increase in moisture in materials stored outdoors decreased the heating value, due to energy consumption for water evaporation. For most biomasses, self-sustaining combustion ceases at around $65 \%$ moisture content on a wet weight basis [7]. Therefore, in management of fuelwood efforts are made to decrease the moisture content through natural drying during storage [22, 23]. Both wetting and drying effects were emphasized in the outdoor conditions in the present study, as the small piles were entirely exposed to percolating rain water, whereas in the laboratory small sample volumes were exposed to the low humidity of the indoor air. The roughly equal, but opposite, relative change of $55 \%$ from the initial effective heating value due to wetting and drying demonstrated the magnitude of possible energetic losses and gains related to moisture control.

On a dry matter basis, the effective heating value of all biomasses studied decreased by roughly $5 \%$ during storage, although the effect was not statistically significant in the outdoor study. This decrease can be attributed to the degradation-induced increase in the ash content of the biomasses [31]. Overall, the effective heating values (dry) determined were in agreement with the typical ranges reported for logging residues, fuelwood, and bark [6, 7, 26, 32]. Variations in values are caused by e.g., wood species, age of the tree (density and wood:bark-ratio), and growing site [32]. Mixing sludge with the bark resulted in roughly a $2-7 \%$ decrease in effective heating value per unit dry mass in comparison with pure bark, which reflects the inherently lower heating value of the sludge. In the true moisture state ('as received' values), this decrease was somewhat higher (8-35\%), as the sludge-containing treatments maintained slightly higher moisture content than pure bark.

In an industrial context, effective heat values in biomasses used as fuel are typically not measured regularly. For example, in the Imatra mill where the raw material for this study was collected, only the dry matter of the fuel being conveyed to the biomass boiler is measured, using a single sample on a daily basis. The control system of the biomass boiler calculates the effective heat value, using the amount of steam produced as the basis for the calculation. However, there are many uncertainties that can affect the calculated heat value, and in real life this is used only as an indicative measure of fuel quality. From the perspective of the pulp and paper industry, this study provides evidence of how much of the energy value is lost during storage of bark and sludge.

In terms of environmental impact, decomposition of wood material is accompanied by emissions of greenhouse gases, namely $\mathrm{CO}_{2}$ and $\mathrm{CH}_{4}[10,33]$. Since the non-fossil $\mathrm{C}$ in pulp mill wood waste is eventually converted to $\mathrm{CO}_{2}$ during combustion, the negative effect of pre-incineration $\mathrm{CO}_{2}$ release is mainly associated with loss of energy, as discussed above. However, the environmental impact of $\mathrm{CH}_{4}$ is many times that of $\mathrm{CO}_{2}$, so $\mathrm{CH}_{4}$ generation in possible anaerobic pockets within the waste piles should be avoided. Cumulative $\mathrm{CH}_{4}$ emissions during the present study were low overall, but inclusion of sludge increased the $\mathrm{CH}_{4}$ emissions over the level in pure bark. It can be assumed that in larger stacks at commercial mills, gas exchange is less efficient and $\mathrm{CH}_{4}$ production is thus more probable. In a life cycle assessment of coppice willow for energy, Whittaker et al. [34] concluded that the greenhouse gas emissions results are highly sensitive to $\mathrm{CH}_{4}$ emissions 
from the storage phase. However, existing estimates on $\mathrm{CH}_{4}$ evolution during wood degradation are uncertain and further research on the topic is required $[34,35]$. Emissions of $\mathrm{N}$-containing gases $\left(\mathrm{N}_{2} \mathrm{O}\right.$ and $\left.\mathrm{NH}_{3}\right)$ were found to be negligible in the present study, which was explained by the high $\mathrm{C}: \mathrm{N}$ ratio of the materials studied (initial C:N ratio ranged roughly between 60 in B50S50 and 130 in B100). In N-limited degradation, there is no release of free ammoniacal- $\mathrm{N}$ for $\mathrm{NH}_{3}$ emissions or nitrate conversion, but nitrogen is immobilized by the degrading microbes [36]. Consequently, practically no inorganic $\mathrm{N}$ was leached with percolating water in the present study.

The characteristics of wood waste leachate are known to depend on the tree species, its state of degradation and volume, and the degree of contact between the percolating water and wood. In general, the main environmental concerns related to the leachate are high loads of organic substances, causing oxygen depletion and toxicity, and the $\mathrm{P}$ content, which contributes to eutrophication of surface waters [12, 37]. In bark extract, the water-soluble COD is comprised mainly of tannins, simple carbohydrates, and phenol monomers [38]. Previously reported COD values for waste waters from bark and wood handling range from below 100 to nearly $15,000 \mathrm{mg} \mathrm{L}^{-1}[12,38]$, so the values obtained here (380-4700 $\mathrm{mg} \mathrm{L}^{-1}$ ) for bark and bark-sludge mixes are rather typical. The cumulative COD over the entire study period was clearly higher for the pure bark than for the bark-sludge mixes. Higher microbial decomposition activity in the mixed biomasses may in part have reduced the availability of labile organic compounds, but their inherent content in the sludge fraction may also have been lower than in the bark.

In contrast to the organic load, higher amounts of inorganic elements tended to be released into percolating water from the sludge-containing materials than from pure bark, probably due both to initially higher concentrations and higher mobility of the elements in the sludge. However, apart from $\mathrm{P}, \mathrm{K}, \mathrm{Na}$, and $\mathrm{S}$, the inorganic elements analyzed proved to be rather non-mobile in all biomasses studied. Interestingly, mixing sludge with bark reduced leaching of $\mathrm{P}$. A probable mechanism is sorption or precipitation of inorganic phosphate-P with $\mathrm{Fe}$, and especially $\mathrm{Al}$, introduced within the sludge, but biological immobilization of P may also have occurred [39]. Aluminum-based chemicals are used in the effluent treatment process at the mill where the study materials were collected, which likely explains the $\mathrm{Al}$ content in the sludge.

\section{Conclusions}

Storing bark combined with sludge in comparison with storing the bark on its own had a negative effect on the total energy content of the biomass. The adverse effect of sludge was caused by the increased rate of degradation, biological activity, and a higher moisture content. From an environmental impact perspective, sludge addition increased emissions of $\mathrm{CH}_{4}$ and the load of most inorganic elements in percolating water. Positive impacts resulting from addition of sludge to bark were a notable decrease in the COD and P content of the leachate. The results also indicated that mixing sludge with bark can result in quite significant loss of total energy content during storage of the biomass. Therefore, the pulp and paper industry should move to adopt other utilization methods for sludge, rather than conventional co-incineration with bark. Use of the sludge in agricultural applications for improving the soil structure and water-holding capacity through increased soil organic matter content, together with simultaneous recycling of nutrients accumulated in the sludge, would be in line with the premise of a sustainable bio-economy $[4,40]$. Other alternative is to combine the energy use and carbon sequestration e.g. through hydrothermal carbonization or hydrothermal liquefaction. Overall, comprehensive life cycle analysis is required for identifying the most feasible future options for pulp and paper mill sludge treatment.

Acknowledgements The technical staff at Luke are acknowledged for their skilled field and laboratory work.

Funding Open Access funding provided by Aalto University. This study was supported by the Finnish Funding Agency for Technology and Innovation (Tekes/Business Finland).

Data Availability Data will be made available upon reasonable request.

Code Availability Not applicable.

\section{Declarations}

Conflict of interest Authors declare that they have no conflict of interest.

Open Access This article is licensed under a Creative Commons Attribution 4.0 International License, which permits use, sharing, adaptation, distribution and reproduction in any medium or format, as long as you give appropriate credit to the original author(s) and the source, provide a link to the Creative Commons licence, and indicate if changes were made. The images or other third party material in this article are included in the article's Creative Commons licence, unless indicated otherwise in a credit line to the material. If material is not included in the article's Creative Commons licence and your intended use is not permitted by statutory regulation or exceeds the permitted use, you will need to obtain permission directly from the copyright holder. To view a copy of this licence, visit http://creativecommons.org/licenses/by/4.0/.

\section{References}

1. Monte, M.C., Fuente, E., Blanco, A., Negro, C.: Waste management from pulp and paper production in the European Union. Waste Manage. 29, 293-308 (2009) 
2. Nurmesniemi, H., Pöykiö, R., Keiski, R.L.: A case study of waste management at the Northern Finnish pulp and paper mill complex of Stora Enso Veitsiluoto Mills. Waste Manage. 27, 1939-1948 (2007)

3. Gavrilescu, D.: Energy from biomass in pulp and paper mills. Environ. Eng. Manage. J. 7, 537-546 (2008)

4. Rasa, K., Pennanen, T., Peltoniemi, K., Velmala, S., Fritze, H., Kaseva, J., Joona, J., Uusitalo, R.: Pulp and paper industry sludges decrease soil erodibility. J. Environ. Qual. 2020, 1-20 (2020)

5. Faubert, P., Barnabe, S., Bouchard, S., Côté, R., Villeneuve, C.: Pulp and paper mill sludge management practices: what are the challenges to assess the impacts on greenhouse gas emissions? Resour. Conserv. Recycl. 108, 107-133 (2016)

6. Krigstin, S., Wetzel, S.: A review of mechanisms responsible for changes to stored woody biomass fuels. Fuel 175, 75-86 (2016)

7. Jenkins, B.M., Baxter, L.L., Miles Jr, T.R., Miles, T.R.: Combustion properties of biomass. Fuel Process. Technol. 54, 17-46 (1998)

8. Alakoski, E., Jämsén, M., Agar, D., Tampio, E., Wihersaari, M.: From wood pellets to wood chips, risks of degradation and emissions from the storage of woody biomass - a short review. Renew. Sustain. Energy Rev. 54, 376-383 (2016)

9. Wihersaari, M.: Evaluation of greenhouse gas emission risks from storage of wood residue. Biomass Bioenergy 28, 444-453 (2005)

10. He, X., Lau, A.K., Sokhansanj, S., Lim, C.J., Bi, X.T., Melin, S.: Dry matter losses in combination with gaseous emissions during the storage of forest residues. Fuel 95, 662-664 (2012)

11. Doig, P., van Poppelen, P., Baldwin, S.A.: Characterization of particles in fresh and primary-treated log sort yard runoff. Water Qual. Res. J. Can. 41, 37-46 (2006)

12. Hedmark, $\AA$, Scholz, M.: Review of environmental effects and treatment of runoff from storage and handling of wood. Bioresour. Technol. 99, 5997-6009 (2008)

13. Masbough, A., Frankowski, K., Hall, K.J., Duff, S.J.B.: The effectiveness of constructed wetland for treatment of woodwaste leachate. Ecol. Eng. 25, 552-566 (2005)

14. Hewitt, L.M., Parrott, J.L., McMaster, M.E.: A decade of research on the environmental impacts of pulp and paper mill effluents in Canada: sources and characteristics of bioactive substances. J. Toxicol. Environ. Health Part B 9, 341-356 (2006)

15. Owens, J.W.: The hazard assessment of pulp and paper effluents in the aquatic environment: a review. Environ. Toxicol. Chem. 10, 1511-1540 (1991)

16. Tao, W., Hall, K.J., Masbough, A., Frankowski, K., Duff, S.J.B.: Characterization of leachate from a woodwaste pile. Water Qual. Res. J. Can. 40, 476-483 (2005)

17. Gbur, E.E., Stroup, W.W., McCarter, K.S., Durham, S., Young, L.J., Christman, M., West, M., Kramer, M.: Analysis of Generalized Linear Mixed Models in the Agricultural and Natural Resources Sciences. American Society of Agronomy, Madison (2012)

18. Westfall, P.H.: Multiple Testing of General Contrasts Using Logical Constraints and Correlations. J. Am. Stat. Assoc. 92, 299-306 (1997)

19. Kenward, M.G., Roger, J.H.: An Improved Approximation to the Precision of Fixed Effects from Restricted Maximum Likelihood. Comput. Stat. Data Anal. 53, 2583-2595 (2009)

20. Ernstson, M.-L., Jirjis, R., Rasmuson, A.: Experimental determination of the degradation rate for some forest residue fuel components at different temperatures and oxygen concentrations. Scand. J. For. Res. 6, 271-287 (1991)

21. Filbakk, T., Høibø, O.A., Dibdiakova, J., Nurmi, J.: Modelling moisture content and dry matter loss during storage of logging residues for energy. Scand. J. For. Res. 26, 267-277 (2011)
22. Petterson, M., Nordfjell, T.: Fuel quality changes during seasonal storage of compacted logging residues and young trees. Biomass Bioenergy 31, 782-792 (2007)

23. Routa, J., Kolström, M., Ruotsalainen, J., Sikanen, L.: Precision measurement of forest harvesting residue moisture change and dry matter losses by constant weight monitoring. Int. J. For. Eng. 26, 71-83 (2015)

24. Ferrero, F., Lohrer, C., Schmidt, B.M., Noll, M., Malow, M.: A mathematical model to predict the heating-up of large-scale wood piles. J. Loss Prev. Process Ind. 22, 439-448 (2009)

25. Krigstin, S., Helmeste, C., Jia, H., Johnson, K.E., Wetzel, S., Volpe, S., Faizal, W., Ferrero, F.: Comparative analysis of bark and woodchip biomass piles for enhancing predictability of selfheating. Fuel 242, 699-709 (2019)

26. Thörnqvist, T.: Drying and storage of forest residues for energy production. Biomass 7, 125-134 (1985)

27. Jirjis, R.: Storage and drying of woof fuel. Biomass Bioenerg. 9, 181-190 (1995)

28. Tremier, A., de Guardia, A., Massiani, C., Paul, E., Martel, J.L.: A respirometric method for characterising the organic composition and biodegradation kinetics and the temperature influence on the biodegradation kinetics, for a mixture of sludge and bulking agent to be co-composted. Bioresour. Technol. 96, 169-180 (2005)

29. Boddy, L.: Carbon dioxide release from decomposing wood: effect of water content and temperature. Soil Biol. Biochem. 15, 501-510 (1983)

30. Moore, A.M.: Temperature and moisture dependence of decomposition rates of hardwood and coniferous leaf litter. Soil Biol. Biochem. 18, 427-435 (1986)

31. Sheng, C., Azevedo, J.L.T.: Estimating the higher heating value of biomass fuels from basic analysis data. Biomass Bioenergy $\mathbf{2 8}$, 499-507 (2005)

32. Klasnja, B., Kopitovic, S., Orlovic, S.: Wood and bark of some poplar and willow clones as fuelwood. Biomass Bioenerg. 23, 427-432 (2002)

33. Mukhin, V.A., Voronin, P.Y.: Methane emission during wood fungal decomposition. Doklady Biol. Sci. 413, 159-160 (2007)

34. Whittaker, C., Macalpine, W., Yates, N.E., Shield, I.: Dry matter losses and methane emissions during wood chip storage: the impact on full life cycle greenhouse gas savings of short rotation coppice willow for heat. Bioenergy Res. 9, 820-835 (2016)

35. O'Dwyer, J., Walshe, D., Byrne, K.A.: Wood waste decomposition in landfills: An assessment of current knowledge and implications for emissions reporting. Waste Manage. 73, 181-188 (2018)

36. Eiland, F., Klamer, M., Lind, A.-M., Leth, M., Bååth, E.: Influence of initial $\mathrm{C} / \mathrm{N}$ ratio on chemical and microbial composition during long term composting of straw. Microb. Ecol. 41, 272-280 (2001)

37. Orban, J.L., Kozak, R.A., Sidle, R.C., Duff, S.J.B.: Assessment of relative environmental risk from logyard run-off in British Columbia. For. Chron. 78, 146-151 (2002)

38. Field, J.A., Leyendeckers, M.J.H., Sierra Alvarez, R., Lettinga, G., Habets, L.H.A.: The methanogenic toxicity of bark tannins and the anaerobic biodegradability of water soluble bark matter. Water Sci. Technol. 20, 219-240 (1988)

39. Güsewell, S., Gessner, M.O.: N: P ratios influence litter decomposition and colonization by fungi and bacteria in microcosms. Funct. Ecol. 23, 211-219 (2009)

40. Cabral, F., Vasconcelos, E., Goss, M.J., Cordovil, C.M.D.S.: The value, use, and environmental impacts of pulp-mill sludge additions to forest and agricultural lands in Europe. Environ. Rev. 6, 55-64 (1998)

Publisher's Note Springer Nature remains neutral with regard to jurisdictional claims in published maps and institutional affiliations. 